\title{
Prevalence of coronary heart disease in Scotland: Scottish Heart Health Study
}

\author{
W C S Smith, M B Kenicer, Hugh Tunstall-Pedoe, E C Clark, I K Crombie
}

\begin{abstract}
Data from 10359 men and women aged 40-59 years from 22 districts in the Scottish Heart Health Study were used to describe the prevalence rates of coronary heart disease in Scotland in 19841986 and their relation to the geographical variation in mortality in these districts. Prevalence was measured by previous history, Rose chest pain questionnaire, and the Minnesota code of a 12 lead resting electrocardiogram. The prevalence of coronary heart disease in Scotland was high compared with studies from other countries that used the same standardised methods. A history of angina was more common in men $(5.5 \%)$ than in women $(3.9 \%)$, though in response to the Rose questionnaire $8 \cdot 5 \%$ of women and $6.3 \%$ of men reported chest pain. A history of myocardial infarction was three times more common in men than women, as was a Q/QS pattern on the electrocardiogram. There were significant correlations between the different measures of coronary prevalence. District measures of angina correlated well with mortality from coronary heart disease, and these correlations tended to be stronger in women than in men. There was no significant correlation between mortality from coronary heart disease and measures of myocardial infarction. The study provides data on the prevalence of coronary heart disease in men and women that are valuable for the planning of cardiological services.
\end{abstract}

Cardiovascular

Epidemiology Unit, Ninewells Hospital and Medical School, Dundee

W C S Smith

M B Kenicer

H Tunstall-Pedoe

E C Clark

I K Crombie

Correspondence to

Dr W C S Smith,

Cardiovascular

Epidemiology Unit,

Ninewells Hospital and

Medical School,

Dundee DD1 9SY.

Accepted for publication 13 June 1990 disease is very high in both sexes ${ }^{1}$ and shows considerable geographical variation. ${ }^{2}$ Mortality statistics are based on the cause of death given by the certifying doctor and certification practice may vary between countries. Within one country, however, the differences in the registration systems and certification patterns are smaller. ${ }^{3}$ Incidence rates of myocardial infarction are another measure for comparing the coronary heart disease experience of different areas. A study in 1967-1968 gave some information on the incidence of myocardial infarction in Edinburgh ${ }^{4}$ and further data are currently being collected in Glasgow as part of the World Health Organisation MONICA project. ${ }^{5}$ This study will allow the incidence of myocardial infarction in different countries to be compared.

Another approach to assessing the extent of coronary heart disease in different countries and in different geographical areas within a country is the estimation of disease prevalence. This uses standardised methods to estimate the proportions of individuals in communities who currently have evidence of coronary heart disease. The Scottish Heart Health Study used three standard epidemiological methods to estimate the prevalence of coronary heart disease. These were the previous medical history, the Rose chest pain questionnaire, and the resting electrocardiogram coded according to the Minnesota code. We used the findings to describe the prevalences of the disease, to examine geographical variations in prevalence in Scotland, and to compare these with measures of coronary heart disease mortality. The results were compared with the prevalence of coronary heart disease found in other studies in other countries when the same methods were used.

\section{Subjects and methods}

METHODS

The measures of coronary heart disease prevalence were based on the Scottish Heart Health Study methods. ${ }^{6}$ In this study a representative sample of men and women aged 40-59 years was drawn randomly from those registered with general practitioners in 22 different districts throughout Scotland. The target number of subjects in each district was 450 with larger numbers of participants in Edinburgh and Glasgow.

Each subject was invited to complete a 
Table 1 Prevalence of coronary heart disease in 22 Scottish districts

\begin{tabular}{|c|c|c|}
\hline & $\begin{array}{l}\text { Men } \\
\text { Median (range) }\end{array}$ & $\begin{array}{l}\text { Women } \\
\text { Median (range) }\end{array}$ \\
\hline $\begin{array}{l}\text { Past medical history (\%): } \\
\text { Angina } \\
\text { Myocardial infarction }\end{array}$ & $\begin{array}{l}5 \cdot 5(2 \cdot 7-9 \cdot 1) \\
4 \cdot 3(2 \cdot 0-8 \cdot 3)\end{array}$ & $\begin{array}{l}3.9(1.4-7.7) \\
1.4(0.3-3.5)\end{array}$ \\
\hline $\begin{array}{l}\text { Rose questionnaire (\%): } \\
\text { Any chest pain } \\
\text { Angina } \\
\text { Angina grade } 1 \\
\text { Angina grade } 2 \\
\text { Possible infarction }\end{array}$ & $\begin{array}{c}29 \cdot 1(21 \cdot 5-39 \cdot 1) \\
6 \cdot 3(3 \cdot 9-14 \cdot 8) \\
4 \cdot 2(2 \cdot 1-9 \cdot 8) \\
2 \cdot 1(0 \cdot 7-5 \cdot 4) \\
7 \cdot 8(5 \cdot 3-13 \cdot 1)\end{array}$ & $\begin{array}{c}24 \cdot 7(14 \cdot 6-34 \cdot 5) \\
8 \cdot 5(4 \cdot 3-17 \cdot 6) \\
6 \cdot 7(3 \cdot 3-12 \cdot 2) \\
2 \cdot 0(0 \cdot 0-6 \cdot 8) \\
5 \cdot 4(2 \cdot 6-8 \cdot 4)\end{array}$ \\
\hline $\begin{array}{l}\text { Electrocardiogram (\%): } \\
\text { Q/QS pattern } \\
\text { Ischaemic (Whitehall) } \\
\text { Major abnormality } \\
\text { Minor abnormality }\end{array}$ & $\begin{array}{c}1 \cdot 7(0 \cdot 0-5 \cdot 1) \\
9 \cdot 8(5 \cdot 4-14 \cdot 1) \\
5 \cdot 9(2 \cdot 8-8 \cdot 6) \\
10 \cdot 7(5 \cdot 7-15 \cdot 7)\end{array}$ & $\begin{array}{l}0 \cdot 5(0 \cdot 0-1 \cdot 7) \\
8 \cdot 7(5 \cdot 5-15 \cdot 0) \\
3 \cdot 8(2 \cdot 1-8 \cdot 9) \\
8 \cdot 0(4 \cdot 3-12 \cdot 4)\end{array}$ \\
\hline $\begin{array}{l}\text { Standardised mortality } \\
\text { ratio }\end{array}$ & $101(61-136)$ & $99(50-147)$ \\
\hline
\end{tabular}

was measured as the percentage of subjects who had a history of angina pectoris or myocardial infarction. The Rose chest pain questionnaire identified the percentage with any chest pain, angina grade 1 and 2 , and possible myocardial infarction. The electrocardiograms were used to identify individuals with a Q/QS pattern (Minnesota codes 1.11.2); ischaemic changes based on the Whitehall ${ }^{9}$ categories (Minnesota codes 1.1-3, 4.1-4, 5.1-3, 7.1); and the major (Minnesota codes 4.1-2, 5.1-2, 6.1-2, 7.1, 2, 4, 8.1, 3) and minor abnormalities (Minnesota codes 1.3, 4.3, 5.3, $6.3,9.1,3.1-2,2.1-2$ ) as used in the Pooling Project $^{10}$ and other studies.

The measures of mortality from coronary heart disease were based on routine death certificate information for men and women and they were indirectly standardised for age over the range 35-64 years by standardised mortality ratios (SMR). We used the Scottish rates as the standard (the SMR for Scotland as a whole is 100), independently for men and women, and coronary heart disease was defined by International Classification of Diseases rubrics $410-414$. The deaths for the years 1979-1983 were combined.
Table 3 Rank correlation between prevalence and standardised mortality ratios for coronary heart disease in 22 Scottish districts

\begin{tabular}{|c|c|c|}
\hline & \multicolumn{2}{|c|}{ Rank correlation coefficient } \\
\hline & Men & Women \\
\hline $\begin{array}{l}\text { Past medical history: } \\
\text { Angina } \\
\text { Myocardial infarction }\end{array}$ & $\begin{array}{l}0.11 \\
0.01\end{array}$ & $\begin{array}{l}0.57 \dagger \\
0.22\end{array}$ \\
\hline $\begin{array}{l}\text { Rose questionnaire: } \\
\text { Any chest pain } \\
\text { Angina } \\
\text { Angina grade } 1 \\
\text { Angina grade } 2 \\
\text { Possible infarction }\end{array}$ & $\begin{array}{l}0.40^{\star} \\
0 \cdot 49^{\star} \\
0 \cdot 36 \\
0 \cdot 43^{\star} \\
0 \cdot 31\end{array}$ & $\begin{array}{l}0.49 \star \\
0.77 \dagger \\
0.67 \dagger \\
0.50 \dagger \\
0.51 \dagger\end{array}$ \\
\hline $\begin{array}{l}\text { Electrocardiogram: } \\
\text { Q/QS pattern } \\
\text { Ischaemia (Whitehall) } \\
\text { Major abnormality } \\
\text { Minor abnormality }\end{array}$ & $\begin{array}{r}0.16 \\
0.16 \\
-0.25 \\
0.11\end{array}$ & $\begin{array}{l}0 \cdot 06 \\
0 \cdot 23 \\
0 \cdot 24 \\
0 \cdot 04\end{array}$ \\
\hline
\end{tabular}

\section{Results}

There were 10359 men and women aged 40-59 years from the 22 selected districts in the Scottish Heart Health Study. The overall response rate was $74 \%$. Table 1 shows the range and median percentages of men and women across the districts who had positive medical histories, positive responses to the Rose questionnaire, and electrocardiographic changes.

The percentage with a history of angina was slightly higher in men than in women and a history of myocardial infarction was about three times more common in men. About a quarter of men and women had at some time suffered from chest pain or discomfort but only a few conformed to the conventional Rose definition of angina. ${ }^{7}$ The percentage of women who were positive for Rose angina was slightly higher than that of men; this difference was attributable to a difference in the less severe (grade 1) angina. A higher proportion of men than women were classified as having possible infarction according to the Rose criteria. The Q/QS pattern was three times more common in men than women but the sex differences in the other electrocardiographic groupings were not so pronounced, with the percentages in men

Table 2 Rank correlation between the different measures of the prevalence of coronary heart disease in 22 Scottish districts

\begin{tabular}{|c|c|c|c|c|c|c|}
\hline & \multicolumn{2}{|c|}{ Past medical history } & \multicolumn{2}{|c|}{ Rose questionnaire } & \multicolumn{2}{|c|}{ Electrocardiogram } \\
\hline & Angina & MI & Angina & MI & $Q / Q S$ & Ischaemia \\
\hline \multirow{4}{*}{$\begin{array}{l}\text { Past medical history: } \\
\text { Angina } \\
\text { MI } \\
\text { Rose questionnaire: } \\
\text { Angina grade 1 } \\
\text { MI } \\
\text { Electrocardiogram: } \\
\text { Q/QS pattern } \\
\text { Ischaemia }\end{array}$} & \multicolumn{4}{|c|}{ Men } & & \\
\hline & - & $\underline{0.66 \dagger}$ & $\begin{array}{l}0.43^{\star} \\
0.12\end{array}$ & $\begin{array}{l}0.54 \dagger \\
0.42^{\star}\end{array}$ & $\begin{array}{l}0.26 \\
0.31\end{array}$ & $\begin{array}{l}0.50 \dagger \\
0.41^{\star}\end{array}$ \\
\hline & & & - & $0.58 \dagger$ & $\begin{array}{l}0.03 \\
0.19\end{array}$ & $\begin{array}{l}0.53 \dagger \\
0.40^{\star}\end{array}$ \\
\hline & & & & & - & $0 \cdot 35$ \\
\hline \multirow{4}{*}{$\begin{array}{l}\text { Past medical history: } \\
\text { Angina } \\
\text { MI } \\
\text { Rose questionnaire: } \\
\text { Angina grade 1 } \\
\text { MI } \\
\text { Electrocardiogram: } \\
\text { Q/OS pattern } \\
\text { Ischaemia }\end{array}$} & \multirow{4}{*}{ - } & & omen & & & \\
\hline & & $0.44^{\star}$ & $\begin{array}{l}0.73 \dagger \\
0.51 t\end{array}$ & $\begin{array}{l}0.52 \dagger \\
0.32\end{array}$ & $\begin{array}{l}0.05 \\
0.33\end{array}$ & $\begin{array}{l}\mathbf{0} \cdot 39 \\
\mathbf{0} \cdot 44^{\star}\end{array}$ \\
\hline & & & - & $0.46^{\star}$ & $\begin{array}{l}0.05 \\
0.11\end{array}$ & $\begin{array}{l}0.22 \\
0.26\end{array}$ \\
\hline & & & & & - & $\underline{0.28}$ \\
\hline
\end{tabular}

$\star_{0.05}>p>0.01$; $\nmid$ p $<0.01$.

MI, myocardial infarction. 
Figure 1 Rose angina (grade 1) and coronary heart disease $S M R$ in men in 22 Scottish districts.

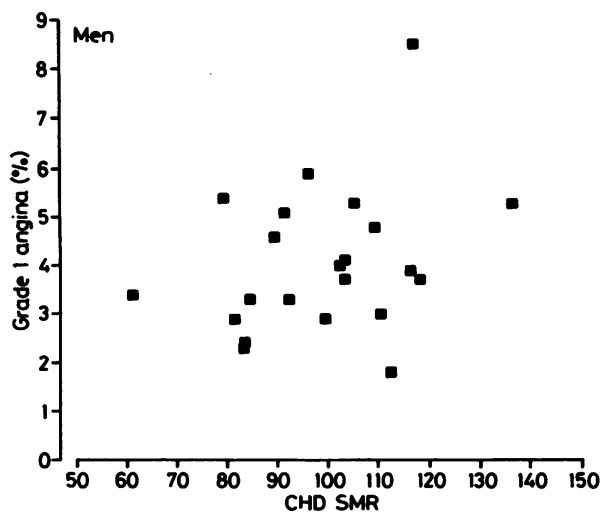

being only slightly higher than those in women.

There was a considerable range of values for all the measures of the prevalence of coronary heart disease across the districts (table 1); the range of the SMRs for coronary heart disease was also wide. The most striking differences between the sexes were in measures of myocardial infarction. Table 2 shows the interrelations between these various measures of prevalence as a matrix of rank coefficients. In men and women across the 22 districts a past medical history of angina related well to a past history of infarction, to the Rose categories, and electrocardiographic ischaemia, but not to the $Q$ / QS pattern. A past history of myocardial infarction did not correlate well with Rose angina in men but showed a relation with other measures both in men and women. The Q/QS pattern showed some correlation with previous infarction but little relation to the other measures, while ischaemic changes correlated with most measures across the districts, with the coefficients for men being similar or greater than those for women.

Table 3 shows the rank correlation of coronary disease SMRs with the various measures of coronary prevalence in men and women across the 22 districts. The relation in women between a past history of angina and the SMR was not seen in men, and there was no relation between previous infarction and mortality. In men the percentages in a district with any chest pain, all angina, and severe grade 2 angina were

Figure 2 Rose angina (grade 1) and coronary heart disease SMR in women in 22 Scottish districts. all related to mortality. In women all the Rose categories correlated with mortality and the correlation coefficients were greater than those for men. Figure 1 shows the relation between grade 1 angina and coronary mortality in men and fig 2 the relation between grade 1 angina and coronary mortality in women across the 22 districts. None of the electrocardiographic groups in men or women showed any relation with mortality.

\section{Discussion}

Symptom questionnaires ${ }^{7}$ were introduced in epidemiological studies because clinical questioning was shown objectively to be inconsistent and unreliable, ${ }^{11}$ and a similar experience with interpretation of the electrocardiogram led to the development of the Minnesota code. ${ }^{8}$ The Rose questionnaire and resting electrocardiogram are standard tests for measuring and comparing prevalence and there is extensive documentation of their sensitivity and specificity. These measures do not have to be correct in every single case but they need to be safe and acceptable for population studies, as well as being robust, repeatable, and with reasonable validity.

The findings of the Scottish Heart Health Study showed the range of values of the different measures of coronary disease prevalence across the Scottish districts. There was a considerable difference between men and women in measures of myocardial infarction but less pronounced differences in measures of angina. Few studies have included women but the Framingham study also showed that the prevalence of angina in women was more equal to that in men than was the incidence of coronary heart attacks, ${ }^{12}$ and that women with angina had a better prognosis. The absolute values for measures of infarction were highest for the Rose possible infarction category and lowest for a Q/QS pattern. Similarly the Rose measures of angina were higher than the percentage with a previous history of angina.

Comparisons between the prevalence of coronary heart disease in the Scottish Heart Health Study and other studies must be interpreted with care despite the use of standardised methods. It is essential that the age groups are comparable because of the important effect of age on prevalence. There are two versions of the Rose chest pain questionnaire: the selfadministered one may yield rates higher than the administered version-although in a recent study they were shown to be similar. ${ }^{13}$ Electrocardiographic findings should only be compared if the grouping of Minnesota codes is identical. The original paper on the Rose selfadministered questionnaire gave angina and possible infarction rates for men of $7.6 \%$ and $6.7 \%$. These are similar to the findings in our study though the age range in the original paper was wider (40-64 years). The Whitehall study showed that $0.7 \%$ of men had a $Q / Q S$ pattern and $6.3 \%$ an electrocardiogram showing ischaemia. ${ }^{14}$ Both these results are lower than the Scottish Heart Health Study; however, the Whitehall study used limb leads, which are less informative than chest leads. ${ }^{15}$ 
In the Pooling Project study $3 \%$ of men aged 40-59 years at entry showed major abnormalities and $9 \%$ showed minor abnormalities on the electrocardiogram ${ }^{10}$; both these results were lower than our findings. The Copenhagen City Heart Study reported values for major and minor electrocardiographic abnormality that were higher than we found and a comparative review reported that many countries had higher levels of minor abnormalities than Scotland and a few, including Finland, had higher levels of major abnormalities. ${ }^{16}$ The WHO Heart Disease Prevention Project used the self-administered Rose questionnaire and found that all five countries had lower values of Rose angina than Scotland and all but Poland had lower levels of possible infarction; $Q / Q S$ changes and ischaemia patterns were less common in all countries than in Scotland. ${ }^{17}$ However, six lead electrocardiograms were used in the WHO project and the participants were employed men. The prevalence findings of the British Regional Heart Study ${ }^{18}$ resemble ours though the method was slightly different. More recently the Caerphilly and Speedwell surveys showed Rose angina and evidence of ischaemia on the electrocardiogram in similar proportions to those reported here but a much higher frequency of $Q / Q S$ changes (3.5-3.9\%) (Minnesota 1.1-2). ${ }^{19}$ Few studies, apart from the Copenhagen study, report findings for women. The Scottish Heart Health Study findings are very similar to the Mid-Span findings ${ }^{20}$ for electrocardiographic abnormalities, and the results for Rose angina and a $\mathrm{Q} / \mathrm{QS}$ pattern were similar to a recent Scottish study. ${ }^{21}$

The interrelations between the measures of prevalence used are valuable in validating each of the three methods. The previous history of angina, Rose angina, and electrocardiographic evidence of ischaemia were all closely interrelated. The Q/QS pattern showed no significant correlation with other measures probably because the number of individuals was small; however, there was a weak relation between the Q/QS pattern and a past history of an infarction in both men and women.

The positive correlations between district measures of mortality and many of the measures of disease prevalence validate the geographical variation in coronary disease within Scotland. These correlations are based on 22 districts with only two to three hundred subjects in each sex per district, which because of the low prevalence for certain presentations will tend to dilute the correlation. In general, the Rose chest pain measures of morbidity related best to mortality and the relation was stronger in women than in men despite the lower specificity of angina for coronary heart disease in women. None of the electrocardiographic measures of prevalence were related to morbidity and only possible infarction reported in the Rose questionnaire in women, of all the measures of infarction, correlated with mortality. This may be because of geographical variation in the pattern of sudden cardiac death. The Scottish Heart Health Study presented detailed information on the extent and geographical variation of risk factors for coronary heart disease. ${ }^{22}{ }^{23}$ The present paper provided data on the prevalence of coronary heart disease in both men and women which will be valuable for the planning of cardiological services.

1 Tunstall-Pedoe H, Smith WCS, Crombie IK. Levels and trends of coronary heart disease mortality in Scotland compared with other countries. Health Bull (Edinb) 1986;44:153-61.

2 Crombie IK, Smith WCS, Kenicer MB, Tunstall-Pedoe H. Geographical variation in coronary heart disease mortality in Scotland. Health Bull (Edinb) 1986;44:193-202.

3 Smith WCS, Tunstall-Pedoe $\mathbf{H}$. European regional variations in cardiovascular mortality. Br Med Bull 1984; 40:374-9.

4 Armstrong A, Duncan B, Oliver MF, et al. Natural history of acute coronary heart attacks. A community study. $\mathrm{Br}$ Heart J 1972;34:67-80.

World Health Organisation Principal Investigator (prepared by Tunstall-Pedoe $H$ ). The World Health Organisation MONICA project (MONItoring trends and determinants in CArdiovascular disease): a major international collaboration. J Clin Epidemiol 1988;41:105-14.

6 Smith WCS, Crombie IK, Tavendale R, Irving JM, Kenice $M B$, Tunstall-Pedoe $H$. The Scottish Heart Health Study: objectives and development of methods. Health Bull (Edinb) 1987;45:211-7.

7 Rose G, McCartney P, Reid DD. Self-administration of questionnaire on chest pain and intermittent claudication. Br J Prev Soc Med 1977;31:42-8.

8 Prineas RJ, Crow RS, Blackburn H. The Minnesota code manual of electrographic findings. Bristol: John Wright, 1982.

9 Rose G, Baxter PJ, Reid DD, McCartney P. Prevalence and prognosis of electrocardiographic findings in middle-aged men. Br Heart J 1978;40:636-43.

10 The Pooling Project Research Group. Relationship of blood pressure, serum cholesterol, smoking habit, relative weight and ECG abnormalities to incidence of majo coronary events: final report of the Pooling Project. J Chronic Dis 1978;31:201-306.

11 Rose G. Chest pain questionnaire. Milbank Mem Fund $Q$ 1965;43:32-9.

12 Kannel WB, Feinleib M. Natural history of angina pectoris in the Framingham Study. Am J Cardiol 1972;29:154-63.

13 Cook DG, Shaper AG, Macfarlane PW. Using the WHO (Rose) angina questionnaire in cardiovascula epidemiology. Int $J$ Epidemiol 1989;18:607-13.

14 Reid DD, Hamilton PJS, Keen H, Brett GZ, Jarrett RJ, Rose G. Cardiorespiratory disease and diabetes among middle-aged male civil servants. Lancet 1974;i:469-73.

15 Grimley Evans J, Tunbridge WMG. Information loss in limb lead electrocardiograms compared with twelve lead tracings in a population survey among the elderly. Age tracings in a popula

16 Ostor E, Jensen SG, Nyboe J, Hansen AT. Electrocardiographic findings and their association with mortality in the Copenhagen City Heart Study. Eur Heart J 1981;2 317-28.

17 WHO European Collaborative Group. Multi-factorial tria in the prevention of coronary heart disease: recruitmen and initial findings. Eur Heart $J$ 1980;1:73-80.

18 Shaper AG, Cook DG, Walker M, Macfarlane PW. Recall of diagnosis by men with ischaemic heart disease. Br Heart 1984;51:606-11.

19 Bainton D, Baker IA, Sweetnam PM, Yarnell JWG, Elwood PC. Prevalence of ischaemic heart disease: the Caerphilly and Speedwell surveys. Br Heart $J$ 1988;59:201-6.

20 Hawthorne VM, Gilmour WH. Relationship of glucose to prevalence of ECG abnormalities at baseline and to 6 year prevalence of ECG abnormalities at baseline and to 6 year
mortality in Scottish males aged 45-64 years. J Chronic Dis 1979;32:787-96.

21 Wood DA, Riemersma RA, Oliver MF, et al. Adipose tissue and platelet fatty acids and coronary heart disease in Scottish men. Lancet 1984;i:117-21.

22 Smith WCS, Tunstall-Pedoe H, Crombie IK, Tavendale $R$ Concomitants of excess coronary deaths-major risk factor and lifestyle findings from 10,359 men and women in the Scottish Heart Health Study. Scott Med J 1989; 34:550-5.

23 Tunstall-Pedoe H, Smith WCS, Crombie IK, Tavendale R Coronary risk factor and lifestyle variation across Scotland: results from the Scottish Heart Health Study. Scott Med J 1989;34:556-60. 